\title{
Learning-induced enhancement of feedback inhibitory synaptic transmission
}

\author{
Inbar Brosh and Edi Barkai ${ }^{1}$ \\ Departments of Neurobiology and Biology, Faculty of Sciences, University of Haifa 31905, Israel
}

\begin{abstract}
Olfactory-discrimination learning results with a series of intrinsic and excitatory synaptic modifications in piriform cortex pyramidal neurons. Here we show that such learning results with long-lasting enhancement of inhibitory synaptic transmission onto proximal dendrites of these pyramidal neurons. Such enhancement is mediated by a strong hyperpolarizing shift in the reversal potential of fast inhibitory postsynaptic potentials (fIPSPs). Moreover, paired-pulse depression of these IPSPs, indicating enhanced GABA release, is also apparent after learning. We suggest that learning is accompanied by long-lasting enhancement of synaptic inhibition onto excitatory neurons, thus compensating for the increase of excitation in these neurons.
\end{abstract}

Olfactory-discrimination learning is accompanied by a series of long-lasting modifications in intrinsic neuronal properties of piriform cortex pyramidal neurons, as well as in their excitatory synaptic inputs (Saar et al. 1998, 1999, 2002; Knafo et al. 2005). Such changes, while required for memory storage, must be counterbalanced by modifications that would prevent overspreading of activity and uncontrolled strengthening of synaptic connectivity (Hasselmo and Barkai 1995).

To fully understand how large neuronal ensembles grow such permanent changes while maintaining their functionality, three components of neuronal excitability and the manner by which their action is combined must be fully described: the excitatory synaptic drive mainly mediated by glutamate receptors, the intrinsic neuronal excitability, and synaptic inhibition mediated by GABA receptors.

To date, most efforts made toward achieving this goal have been concentrated on describing the mechanisms underlying activity-dependent long-term modifications in the strength of excitatory synaptic connections (Bliss and Collingridge 1993; Malenka and Bear 2004) and in intrinsic neuronal excitability (Saar and Barkai 2003; Zhang and Linden 2003).

Since excitatory synaptic transmission and neuronal excitation are both enhanced by learning, the cortex may enter into an overexcited state, which is bound to impair efficient memory storage (Hasselmo and Barkai 1995). Strengthening inhibition is one possible mechanism for restoring the balance between excitation and inhibition, thus preserving the neuronal network set point and preventing epileptic-like activity.

Activity-induced modulation of inhibitory synaptic transmission has been shown in several brain regions of the mammalian brain (Grunze et al. 1996; Komatsu and Yoshimura 2000; Holmgren and Zilberter 2001). Such long-lasting plasticity of GABAergic synaptic transmission is crucially dependent on calcium entry into the postsynaptic neuron (for review, see Gaiarsa et al. 2002). Both presynaptic and postsynaptic mechanisms are implicated in the process. For example, activity-induced enhancement in the number of $\mathrm{GABA}_{\mathrm{A}}$ receptors was shown in the hippocampus after kindling (Nusser et al. 1998), and enhanced GABA release was shown after brain-derived neurotrophic factor (BDNF) application (Ohba et al. 2005). In addition, in vitro studies

\footnotetext{
'Corresponding author.
}

E-mail ebarkai@research.haifa.ac.il; fax 972-8-8288108.

Article is online at http://www.learnmem.org/cgi/doi/10.1101//m.1430809. have shown in CA1 pyramidal neurons an LTP-induced, positivedirected shift in the reversal potential of the $\mathrm{GABA}_{\mathrm{A}}$-mediated $\mathrm{Cl}^{-}$current (Rivera et al. 2004; Fiumelli et al. 2005).

Here we show that olfactory-discrimination learning is accompanied by a robust long-lasting enhancement of $\mathrm{GABA}_{\mathrm{A}^{-}}$ mediated activity in piriform (olfactory) cortex pyramidal neurons. Such enhancement is due to both presynaptic and postsynaptic modulation of inhibitory synaptic transmission to pyramidal neurons.

Young, adult, water-deprived Sprague-Dawley male rats, at the age of $4 \mathrm{wk}$ at the beginning of training, were trained with 20 trials per day as previously described (Saar et al. 1998, 1999). In short, the rat is positioned at the center of a four-arm maze. An electronic "start" command releases two streams of pressured air into two randomly picked arms: a stream with positive-cue odor into one of the arms, and one with negative-cue odor into another. The rat can choose to enter one of the arms to be rewarded at the far end with a drop of drinking water. Rats in the trained group are rewarded only in the positive-cue containing arm. Pseudo-trained rats are rewarded randomly. Naïve rats are not exposed to the maze. A fan is operated between trials, to clear the air. Once all the trained rats have met the criterion for learning the first pair of odors (at least $80 \%$ positive-cue choices in a day), on the next day both trained and pseudo-trained groups resume training with a new pair of unfamiliar odors. Rats were trained with two pairs of odors to ensure rule learning.

As previously described (Saar et al. 1999), rats indeed learned the second pair of odors much faster than the first pair (7-8 d of training for the first pair and 1-2 $\mathrm{d}$ for the second pair). These data confirm our previous observation, that there are two phases of olfactory-discrimination learning, each with a distinct time course: a first phase during which the animal gradually acquires the appropriate behavioral strategy for completing the task (rule learning), and a second phase when the subject quickly acquires specific odor/reward associations (pair learning). Pseudo-trained rats received that same number of runs.

Animals were sacrificed $5 \mathrm{~d}$ after training completion, when olfactory learning-induced enhancement of excitatory synaptic transmission in the piriform cortex is at its peak (Saar et al. 1999). Experiments were done blind; the group affiliation of the rats (naïve, trained, or pseudo-trained) was unknown to the person conducting the experiments and measurements. Rats were anesthetized with pentobarbital $(60 \mathrm{mg} / \mathrm{kg})$, the brain was removed, and coronal brain slices of $400 \mu \mathrm{m}$ were cut as previously described 
(Saar et al. 1999). Brain slices were kept in oxygenated $\left(95 \% \mathrm{O}_{2}+\right.$ $5 \% \mathrm{CO}_{2}$ ) artificial cerebrospinal fluid (ACSF) containing $\mathrm{NaCl} 124$ $\mathrm{mM}, \mathrm{KCl} 3 \mathrm{mM}, \mathrm{MgSO}_{4} 2 \mathrm{mM}, \mathrm{NaH}_{2} \mathrm{PO}_{4} 1.25 \mathrm{mM}, \mathrm{NaHCO}_{3} 26$ $\mathrm{mM}, \mathrm{CaCl}_{2} 2 \mathrm{mM}$, and glucose $10 \mathrm{mM}$.

Layer II pyramidal neurons receive inhibitory synaptic inputs from two sources; feed-forward (FF) inhibition is evoked by afferent inputs arriving at layer Ia via GABAergic neurons located in layer I, while feedback (FB) inhibition is evoked by layer II pyramidal neurons via GABAergic neurons located in layer III. Inhibitory synaptic transmission is morphologically segregated; FF inhibition is terminated on the distal portion of the apical dendrite, while $\mathrm{FB}$ inhibition is terminated on the proximal dendrites (Suzuki and Bekkers 2007). Consequently, DC current passed via the sharp recording electrode would be much more efficient in modifying the neuron's membrane potential at the locations where FB inhibition is generated. Thus, the stimulation electrode was placed just under layer II, at the border of layer III (Fig. 1A), to evoke only FB inhibition. Synaptic stimuli were applied at layer III at a frequency of $0.05 \mathrm{~Hz}$.

Intracellular current clamp recordings were performed in layer II pyramidal neurons using sharp microelectrodes; $4 \mathrm{M}$ $\mathrm{K}$-acetate electrodes were used to determine the reversal potential of IPSPs, while $3 \mathrm{M} \mathrm{KCl}$ electrodes were used for paired-pulse facilitation (PPF) and paired-pulse depression (PPD) measurements.

To block AMPA- and NMDA-dependent glutamatergic transmission, DNQX $(20 \mu \mathrm{M})$ and APV $(50 \mu \mathrm{M})$ were added to ACSF in all experiments, thus allowing the generation of pure inhibitory postsynaptic potentials (IPSPs). The $\mathrm{GABA}_{\mathrm{A}}$ blocker BMI $(20 \mu \mathrm{M})$ was added at the end of IPSPs recordings; as a result, evoked synaptic activity was always abolished.

Membrane potential was shifted to different values by applying DC current via the recording electrode. Six to 10 synaptic responses were evoked at and digitally averaged to produce the measured response for each membrane potential. The reversal potential of the synaptic response was interpolated with a linear fit of the graph describing the synaptic response as the function of the membrane potential. In each cell, IPSPs were recorded in five to six different membrane potentials. The IPSP amplitude was measured at the first peak after stimulation, which usually occurred with a delay of 7-15 msec from synaptic stimulation.

PPF and PPD were measured in response to two stimuli, with an interstimulus interval of 50 msec. For all PPF and PPD measurements, neurons were recorded at a membrane potential of $-80 \mathrm{mV}$.
A

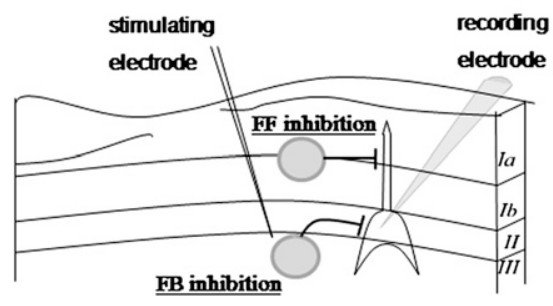

B

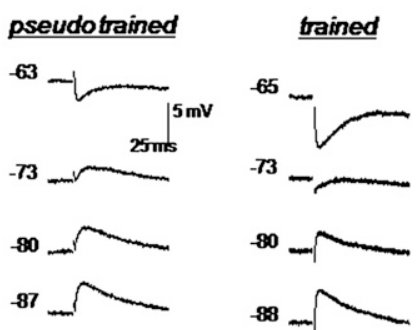

Figure 1. Feedback (FB) synaptic inhibition in layer II pyramidal neurons. $(A)$ Schematic illustration of the piriform cortex in coronal brain slice and the experimental procedure. Intracellular recordings were performed from cell bodies in layer II. Feed-forward inhibition (FF inhibition) inputs are terminated on the distal apical dendrite, while FB inhibition is terminated on cell bodies and proximal dendrites of the cell (Suzuki and Bekkers 2007). Electrical stimuli were applied to the border between layers II and III, in the presence of the glutamatergic AMPA and NMDA receptors blockers, to activate only the FB inhibitory interneurons. $(B)$ Recordings at different membrane potentials in a neuron from a pseudotrained rat (left) and a neuron from a trained rat (right). The reversal potential of the IPSP in the control neuron is at $-69 \mathrm{mV}$; in the trained neuron, $-75 \mathrm{mV}$. Numbers to the left of traces note the holding membrane potential.
For all the electrophysiological measurements, betweengroups comparison was done using one-way ANOVA for the three groups (naïve, trained, and pseudo-trained), and post-hoc multigroups. Values throughout the text are presented as mean \pm SD. ata in graphs are presented as $\pm \mathrm{SE}$.

Typical examples of neurons from one naïve and one trained rat are shown in Figure 1B. The averaged reversal potential of $\mathrm{GABA}_{\mathrm{A}}$-mediated fast IPSPs was significantly lower after learning $(-77.1 \pm 5.3 \mathrm{mV}, n=16$ for trained vs. $-70.4 \pm 7.2 \mathrm{mV}, n=17$ for $2 \mathrm{~A})$. Moreover, such learning-induced reduction is apparent throughout the recorded neuronal population, as shown in the mulative frequency graph (Fig. 2B). (n) that glutamatergic synaptic release is enhanced after learning Het synapses terminating on the same neurons (Fig. 3A), using $3 \mathrm{M}$ filled KCK electrodes to depolarize the reversal potential of the GABA-dependent chloride current. Paired-pulse ratio (PPR) was interval of $50 \mathrm{msec}$. Neuron was recorded at membrane potential of $-80 \mathrm{mV}$. Each trace is a digital average of 10 responses to stimuli $0.1 \mathrm{~Hz}$. In neurons from control rats, a moderate IPSP facilitation was apparent at an interstimulus interval of $50 \mathrm{msec}$ 1/IPSP2 ratio of $1.05 \pm 0.17, n=6$ for naïve and $1.08 \pm 0.14$, $n=7$ for pseudo-trained). This value was significantly higher $(P<$ 0.05 ) compared to neurons from trained rats, where clear PPD was (IPSP1/IPSP2 ratio of $0.86 \pm 0.12, n=6$; Fig. 3B).

We have previously shown that olfactory-discrimination in intrinsic neuronal excitability (Saar and Barkai 2003) excitatory synaptic connectivity (Saar et al. 1999, 2002; Knafo et al. 2005). Such learning-induced modifications in synaptic responses are due to modulation of synaptic transmission rather neurons' resting potential, input resistance, and membrane time constants (Saar et al. 1999). Here we show that inhibitory synaptic synaptic excitation. Similar to olfactory learning-induced modifications in synaptic excitation (Saar et al. 1998, 1999, 2002; Knafo et al. 2005), synaptic inhibition is enhanced throughout the pyramidal cell population. These findings indicated that such modifications in inhibitory synaptic transmission serve as a mechanism that enables the cortical network to maintain a "learning mode" without entering into an hyperexcitable state, in which memories are stored rapidly and efficiently, rather than a mechanism for storing memories for specific odors.

The strong hyperpolarizing shift in the GABA reversal potential observed after learning indicates that the chloride gradient in layer II pyramidal neurons is shifted toward a hyperpolarized value after learning. An opposite, positivedirected shift in the reversal potential of the $\mathrm{GABA}_{\mathrm{A}}$-mediated $\mathrm{Cl}^{-}$current in hippocampal neurons was observed following postsynaptic activation (Fiumelli et al. 2005) and interictal-like activity (Rivera et al. 2004). Such activity-induced 
A

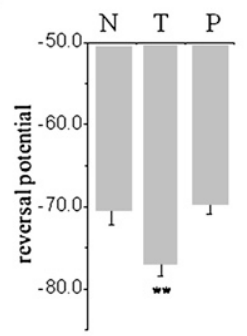

B

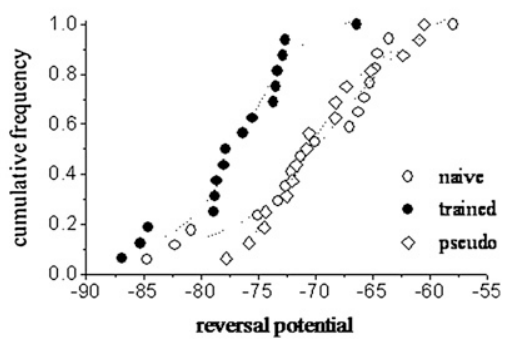

Figure 2. Learning-induced hyperpolarization of the fast IPSPS reversal. $(A)$ Averaged values of the IPSPs reversal potential in the three experimental groups $(\mathrm{N}$, naïve; $\mathrm{T}$, trained; $\mathrm{P}$, pseudo-trained). This value is significantly lower for the neurons taken from trained rats $\left({ }^{* *} P<0.01\right)$. Data for the IPSPs reversal potential were taken from six naive rats, six trained rats, and seven pseudo-trained rats. Values represent mean $\pm \mathrm{SE}$. (B) A cumulative frequency graph comparing the reversal potentials of the fast IPSP in neurons from controls vs. trained rats. Each point represents $\mathrm{VCl}$, the reversal potential of the fast IPSP for a neuron. Notably, the curve for the trained group is shifted smoothly leftward. Only one out of 13 trained neurons has a value higher than the mean or the median of the controls.

shift in the GABA reversal potential is caused by down-regulation of the main chloride transporter found in mature neurons-the $\mathrm{KCC} 2 \mathrm{~K}^{+}-\mathrm{Cl}^{-}$co-transporter, in a BDNF-dependent mechanism (Wardle and Poo 2003; Rivera et al. 2004). Taken together, these findings indicate that learning-induced enhanced activation of the KCC2 co-transported is a likely mechanism for maintaining such long-lasting modulation in the IPSPs reversal potential.

While in neurons from control rats moderate PPF occurs in the inhibitory synapses terminating on pyramidal neurons, PPD in these synapses becomes apparent after learning. By the use of dual recordings of unitary inhibitory synaptic currents in interneuron-pyramidal cell pairs in the hippocampus, Jiang et al. (2000) showed that PPD of the synaptic inhibition occurs at synapses with high initial release probability. Thus, our results indicate that olfactory-discrimination learning is accompanied by long-lasting enhancement in synaptic GABA release, similar to that which occurs in glutamatergic synapses (Saar et al. 1999; Brosh et al. 2007; Cohen-Matsliah et al. 2008). Learning-induced enhanced release in inhibitory synapses was also shown in the cerebellum following fear conditions, where the frequency (but not amplitude) of synaptic inhibitory events was increased (Scelfo et al. 2008).

A shift in the $\mathrm{GABA}_{\mathrm{A}}$-induced reversal potential occurs during normal development, when it is transformed from depolarizing to hyperpolarizing (Ben-Ari 2002; Payne et al. 2003). This change also occurs due to the activation of the chloride co-transporter KCC2 (Ben-Ari 2002; Payne et al. 2003; Blaesse et al. 2006). Thus, learning-induced modulation of the IPSPs reversal potential seems to renew a developmental process. Similarly, enhanced synaptic inhibitory release also occurs in the course of normal development (Morales et al. 2002).

Learning-induced modifications in the predisposition for LTP and LTD are also similar to those that appear during development (Lebel et al. 2001), and occur via the same molecular mechanism-modulation in the subunit composition of the NMDA receptor (Quinlan et al. 2004). Learning-induced modulation of intrinsic neuronal properties also seems to extend a developmental process, in which neurons become more excitable and enhance their spike firing frequency (Lorenzon and Foehring 1993; Saar and Barkai 2003). Thus, our data support the notion that normal development and long-term memory formation share common biological mechanisms.

As noted above, olfactory-discrimination rule learning is accompanied by a series of cellular modifications that occur throughout the neuronal network and strongly enhance its excitability (Saar et al. 1998, 1999, 2002; Knafo et al. 2005). A parallel enhancement in synaptic inhibition, such that would be present during the time period when excitatory changes are still apparent, would act to prevent overexcitation. We found that enhanced synaptic inhibition is present $5 \mathrm{~d}$ after rule learning completion, outlasting learning-induced enhancement of intrinsic neuronal excitability (Saar et al. 1998) and increased spine density along pyramidal neurons apical dendrites (Knafo et al. 2005).

What is the functional role of long-lasting enhancement of synaptic inhibition in learning? While long-term memory maintenance is usually attributed to strengthening of synaptic excitation, such increased excitation must be balanced by additional processes that would compensate for overexcitation. We propose that enhanced inhibition is one such process. We have previously shown that learning is also accompanied by an increase in the threshold for further synaptic enhancements (Rioult-Pedotti et al. 2000; Lebel et al. 2001). Learning-induced increase in the threshold for further synaptic strengthening was attributed to modifications in the subunit composition of the NMDA receptor (Quinlan et al. 1999, 2004; Castellani et al. 2001). Learninginduced enhancement of synaptic inhibition may be an additional mechanism by which undesirable synaptic connectivity is prevented.

In particular, unbalanced simultaneous enhancement of intrinsic neuronal excitability (Saar et al. 1998), enhanced synaptic release (Saar et al. 1999), increased number of synaptic connections (Knafo et al. 2005), and increased postsynaptic conductance of EPSPs (Saar et al. 2002) are bound to result in nondiscriminative strengthening of excitatory synaptic connectivity. Such acrossthe-board enhancement unavoidably results with loss of ability to store distinct memories (Barkai et al. 1994; Hasselmo and Barkai 1995). From this perspective, learning-induced modulation of synaptic inhibition is crucial for maintaining well-tuned network function after learning, no less than modifications in excitatory synaptic connectivity.

To conclude, our study shows that olfactory-discrimination learning results in enhanced inhibitory synaptic transmission. Such enhancement occurs due to postsynaptic as well as presynaptic modifications and serves to counterbalance overexcitation.
A

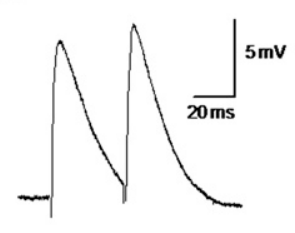

B

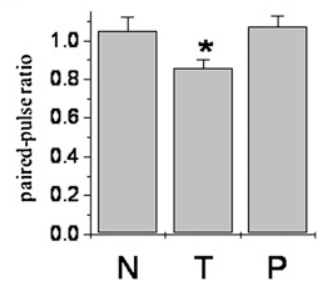

Figure 3. Learning-induced reduction in paired-pulse ratio (PPR). ( $A$ ) PPR was measured in response to two stimuli, with an interstimulus interval of $50 \mathrm{msec}$. Neuron was recorded at membrane potential of $-80 \mathrm{mV}$. The presented trace is a digital average of 10 responses to stimuli applied at $0.1 \mathrm{~Hz}$. Recordings were performed with $3 \mathrm{M} \mathrm{KCl}$ containing a microelectrode to shift the reversal potential of the chloride ion to a depolarizing value. (B) As previously reported for excitatory synaptic transmission (Saar et al. 1999), the mean PPR of the GABA-evoked synaptic response in neurons from trained rats was significantly smaller compared to that in neurons from naïve and pseudo-trained rats. PPR was measured in neurons from five naïve rats, five trained rats, and five pseudo-trained rats. Values represent mean $\pm S E$. ( $N$, naïve; $T$, trained; $P$, pseudo-trained.) $\left(^{*}\right)$ $P<0.05$. 


\section{References}

Barkai E, Bergman RE, Horwitz G, Hasselmo ME. 1994. Modulation of associative memory function in a biophysical simulation of rat piriform cortex. J Neurophysiol 72: 659-677.

Ben-Ari Y. 2002. Excitatory action of GABA during development: The nature of the nurture. Nat Rev Neurosci 3: 728-739.

Blaesse P, Guillemin I, Schindler J, Schweizer M, Delpire E, Khiroug L, Friauf E, Nothwang HG. 2006. Oligomerization of KCC2 correlates with development of inhibitory neurotransmission. JNeurosci 26: 10407-10419.

Bliss TV, Collingridge GL. 1993. A synaptic model of memory: Long-term potentiation in the hippocampus. Nature 361: 31-39.

Brosh I, Rosenblum K, Barkai E. 2007. Learning-induced modulation of SK channels-mediated effect on synaptic transmission. Eur J Neurosci 26: 3253-3260.

Castellani GC, Quinlan EM, Cooper LN, Shouval HZ. 2001. A biophysical model of bidirectional synaptic plasticity: Dependence on AMPA and NMDA receptors. Proc Natl Acad Sci 98: 12772-12777.

Cohen-Matsliah S, Seroussi Y, Rosenblum K, Barkai E. 2008. Persistent ERK activation maintains learning-induced long-lasting modulation of synaptic transmission. Learn Mem 15: 756-761.

Fiumelli H, Cancedda L, Poo MM. 2005. Modulation of GABAergic transmission by activity via postsynaptic $\mathrm{Ca}^{2+}$-dependent regulation of KCC2 function. Neuron 48: 773-786.

Gaiarsa JL, Caillard O, Ben-Ari Y. 2002. Long-term plasticity at GABAergic and glycinergic synapses: Mechanisms and functional significance. Trends Neurosci 25: 564-570.

Grunze HC, Rainnie DG, Hasselmo ME, Barkai E, Hearn EF, McCarley RW, Greene RW. 1996. NMDA-dependent modulation of CA1 local circuit inhibition. I Neurosci 16: 2034-2043.

Hasselmo ME, Barkai E. 1995. Cholinergic modulation of activitydependent synaptic plasticity in the piriform cortex and associative memory function in a network biophysical simulation. J Neurosci 15: 6592-6604.

Holmgren CD, Zilberter Y. 2001. Coincident spiking activity induces longterm changes in inhibition of neocortical pyramidal cells. J Neurosci 21: 8270-8277.

Jiang K, Sun S, Nedergaard M, Kang J. 2000. Paired-pulse modulation at individual GABAergic synapses in rat hippocampus. J Physiol 532: 425 439.

Knafo S, Libersat F, Barkai E. 2005. Dynamics of learning-induced spine redistribution along dendrites of pyramidal neurons. Eur J Neurosci 21 : 927-935.

Komatsu Y, Yoshimura Y. 2000. Activity-dependent maintenance of longterm potentiation at visual cortical inhibitory synapses. J Neurosci 20: 7539-7546.

Lebel D, Grossman Y, Barkai E. 2001. Predisposition for LTP and LTD is modified in the piriform cortex after odor learning. Cereb Cortex 11: $485-489$.

Lorenzon NM, Foehring RC. 1993. The ontogeny of repetitive firing and its modulation by norepinephrine in rat neocortical neurons. Brain Res Dev Brain Res 73: 213-223.
Malenka RC, Bear MF. 2004. LTP and LTD: An embarrassment of riches. Neuron 44: 5-21.

Morales B, Choi SY, Kirkwood A. 2002. Dark rearing alters the development of GABAergic transmission in visual cortex. J Neurosci 22: 80848090

Nusser Z, Hajos N, Somogyi P, Mody I. 1998. Increased number of synaptic $\mathrm{GABA}_{\mathrm{A}}$ receptors underlies potentiation at hippocampal inhibitory synapses. Nature 395: 172-177.

Ohba S, Ikeda T, Ikegaya Y, Nishiyama N, Matsuki N, Yamada MK. 2005. BDNF locally potentiates GABAergic presynaptic machineries: Targetselective circuit inhibition. Cereb Cortex 15: 291-298.

Payne JA, Rivera C, Voipio J, Kaila K. 2003. Cation-chloride co-transporters in neuronal communication, development and trauma. Trends Neurosci 26: 199-206.

Quinlan EM, Philpot BD, Huganir RL, Bear MF. 1999. Rapid, experiencedependent expression of synaptic NMDA receptors in visual cortex in vivo. Nat Neurosci 2: 352-357.

Quinlan E, Lebel D, Brosh I, Barkai E. 2004. A molecular mechanism for stabilization of learning-induced synaptic modifications. Neuron 41: 185-192.

Rioult-Pedotti MS, Friedman D, Donoghue JP. 2000. Learning-induced LTP in neocortex. Science 290: 533-536.

Rivera C, Voipio J, Thomas-Crusells J, Li H, Emri Z, Sipila S, Payne JA Minichiello L, Saarma M, Kaila K. 2004. Mechanism of activitydependent down-regulation of the neuron-specific K-Cl co-transporter KCC2. J Neurosci 24: 4683-4691.

Saar D, Barkai E. 2003. Long-term modifications in intrinsic neuronal properties and rule learning in rats. Eur J Neurosci 17: 2727-2734.

Saar D, Grossman Y, Barkai E. 1998. Reduced after-hyperpolarization in rat piriform cortex pyramidal neurons is associated with increased learning capability during operant conditioning. Eur J Neurosci 10: 1518-1523.

Saar D, Grossman Y, Barkai E. 1999. Reduced synaptic facilitation between pyramidal neurons in the piriform cortex after odor learning. J Neurosci 19: $8616-8622$.

Saar D, Grossman Y, Barkai E. 2002. Learning-induced enhancement of postsynaptic potentials in pyramidal neurons. J Neurophysiol 87: 23582363.

Scelfo B, Sacchetti B, Strata P. 2008. Learning-related long-term potentiation of inhibitory synapses in the cerebellar cortex. Proc Natl Acad Sci 105: 769-774.

Suzuki N, Bekkers JM. 2007. Inhibitory interneurons in the piriform cortex. Clin Exp Pharmacol Physiol 34: 1064-1069.

Wardle RA, Poo MM. 2003. Brain-derived neurotrophic factor modulation of GABAergic synapses by postsynaptic regulation of chloride transport. I Neurosci 23: 8722-8732.

Zhang W, Linden DJ. 2003. The other side of the engram: Experiencedriven changes in neuronal intrinsic excitability. Nat Rev Neurosci 4: 885-900.

Received March 22, 2009; accepted in revised form April 30, 2009. 


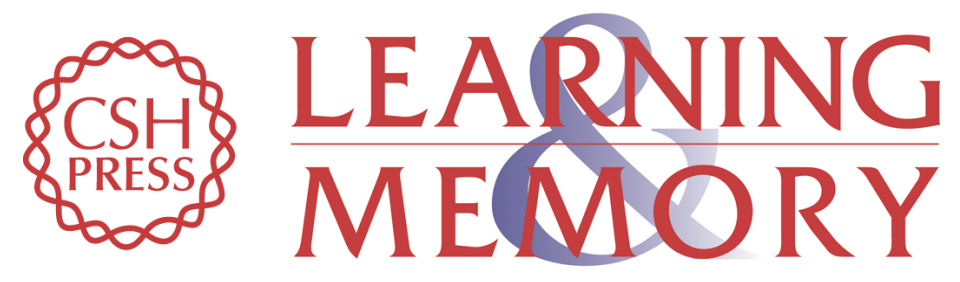

\section{Learning-induced enhancement of feedback inhibitory synaptic transmission}

Inbar Brosh and Edi Barkai

Learn. Mem. 2009, 16:

Access the most recent version at doi:10.1101//m.1430809

References This article cites 34 articles, 13 of which can be accessed free at:

http://learnmem.cshlp.org/content/16/7/413.full.html\#ref-list-1

License

Email Alerting Receive free email alerts when new articles cite this article - sign up in the box at the Service top right corner of the article or click here. 